perficial and randomly built. For the bearer of humanitarian culture, the ability to look at the world "synthetically" was basic, which means seeing objects and phenomena in their entirety. The practices of working with information has become primarily analytical for a representative of the mosaic culture, which exacerbates the a person's alienation from themself.

Unlike the "industrial" education aimed at creating a scientific picture of the world, the education in the 21st century should be supplemented by the study of art, which initiates creative work with holistic, harmonious images and restores the synthetic vision of the world essential for representatives of the mosaic culture. The author concludes that the study of art will be able to help a person who reaches the point of psychological and existential bifurcation to maintain their substantial image.

Keywords: art; substantial image of a person; identity; participation

\title{
REFERENCES
}

Leont'ev, D. A. (2007) Voskhozhdenie k ekzistentsial'nomu miroponimaniiu. In: Tret'ia Vserossiiskaia nauchno prakticheskaia konferentsiia po ekzistentsial' noi psikbologii: materialy soobshchenii./ ed. by D. A. Leonteva. Moscow, Meaning. 188 p. Pp. 3-12. (In Russ.).

Moles, A. (2008) Sotsiodinamika kul'tury. Moscow, LKI. 416 p. (In Russ.).

Samokhvalova, V. I. (1998) O metafizicheskom smysle garmonii. Kul'turno-prosvetitel' skii zhurnal Del'fis, no 16 (3/1998). [online] Available at: http://www.delphis.ru/journal/article/ometafizicheskom-smysle-garmonii [archived in WebCite] (accessed 10.10.2018) (In Russ.).

Stepin, V. S. (2000) Teoreticheskoe znanie. Moscow, Progress Tradition. 744 p. (In Russ.).

Csikszentmihalyi, M. (2017) Kreativnost': Psikbologiia otkrytii i izobretenii. Moscow, Career Press. 528 p. (In Russ.).

Shestakov, V. P. (1983) Esteticheskie kategorii. Moscow, Art. 358 p. (In Russ.).

Submission date: 25.10.2019.

Кожаринова Анна Ростиславовна - кандидат философских наук, доцент кафедры философии, культурологии и политологии Московского гуманитарного университета. Адрес: 111395 , Россия, г. Москва, ул. Юности, д. 5. Тел.: +7 (499) 374-55-11. Эл. адрес: anna_adv@inbox.ru

Kozharinova Anna Rostislavovna, Candidate of Philosophy, Associate Professor, Department of Philosophy, Culturology and Politology, Moscow University for the Humanities. Postal address: 5, Yunosti St., Moscow, Russian Federation, 111395. Tel.: +7 (499) 374-55-11. E-mail: anna_adv@ inbox.ru

DOI: $10.17805 /$ zpu.2020.1.17

\section{Вузовская среда и мера воспитанности студентов}

\author{
Б. Ф. УСМАНОВ
}

МОСКОВСКИЙ ГУМАНИТАРНЫЙ УНИВЕРСИТЕТ

В статье представлено авторское мнение о том, какая система ценностей и взглядов нужна образовательным заведениям России, которым Федеральный закон «Об образовании в Российской Федерации", вступивший в силу с 1 сентября 2013 г., вернул функцию воспитания. Автор размышляет: есть ли у нынешней российской системы образования главенствующая идея и как измерять сегодня воспитанность студента. При этом в подтексте вопрос вопросов: для кого (или для чего) учим и воспитываем? 
По мнению автора, главный критерий, а с ним и признак воспитанности выпускника высшей школы - способность понимать и воспроизводить социальные образцы во имя достижения целей общественного развития, единства личных и общественных интересов, демонстрировать приверженность гражданственности, патриотизму, нравственным нормам и ценностям своего народа, законам страны.

Ключевые слова: вузовская среда; воспитывающая среда; проблема воспитания; мера воспитанности; высшее образование; традиции воспитания; российское образование

\section{ВВЕАЕНИЕ}

$\mathrm{M}$ ало кто сегодня вспоминает о традициях воспитания, строгих дисциплинарных требованиях, общем целеполагающем и взыскательном порядке в императорских учебных заведениях дореволюционной поры. Зато немало желающих исподволь бросить тень на недавнюю советскую образовательную систему за будто бы ее чрезвычайное пристрастие к воспитательным функциям, апологетику политико-патриотических мотивов, перебор с идеологизацией учебных программ.

С актуализацией проблем гражданской ответственности школы и повышения роли молодых специалистов снова так или иначе, порой довольно резко, обозначают себя противники тех принципов в организации образовательного процесса, когда воспитание, говоря словами Сен-Симона, выступает как непрерывное приобретение знаний, «которые совершенно необходимы для поддержания отношений, сложившихся между членами общества» (Великие мыслители ..., 2015: 49). И когда абсолютно непререкаемо действует канон российской императрицы Екатерины II: «Правила воспитания суть первые основания, приуготовляющие нас быть гражданами» (Студенту-первокурснику ..., 2016: 27).

Цель данной статьи - на основе анализа имеющихся в научной литературе подходов разработать систему показателей (ориентиров) для оценки уровня воспитанности студентов в современном вузе.

\section{ПАТРИОТИЗМ - КАТЕГОРИЯ НРАВСТВЕННОСТИ}

Совсем не наивным и не безобидным предстает отъем воспитания у действовавшей образовательной системы, пришедшийся на переходный период. После 1991 г. (распада СССР) страна синхронно лишилась и государственной идеологии, и производной от нее воспитательной парадигмы, исходя из которой долгие десятилетия утверждали себя четко ориентированные морально-нравственные, политические, гражданские и военно-патриотические ценности. В результате отказа от общественных целей мы имеем вызывающее падение нравов, многочисленные факты хамского отношения учащихся к педагогам, неприкрытое стремление выпускников вузов искать работу или продолжение учебы за границей, явный дефицит у них патриотизма, гражданской стойкости, уважения к себе и своим родовым, семейным корням. Режим анархии в воспитании, либерализация системы образования до уровня потребительского рынка привели к утверждению в общественном сознании главенства принципа «Все покупается - все продается».

Чтобы не быть декларативным, сошлюсь на некоторые созвучные теме свидетельства. Эпизод из телефильма: в классе, где учится мальчик киногероини, провели опрос, кто кем желает быть после школы, и выяснилось, что 23 ученика (подавляющее большинство!) хотят стать бандитами и проститутками - т. е. готовы к процессу купли-продажи, аморальному образу жизни. Буквально на следующий день после телефильма читаю в газете выдержки из объявлений на интернет-сайтах: «Я из Рос- 
сии, мне 19 лет. Ищу работу - любую! Я учусь в университете на экономиста, но не хочу им работать»; «Ищу работу в США, сама из России, но сейчас живу в Польше, недавно получила диплом бакалавра, обучение было на английском языке». Еще два типичных воззвания: «Выпускник престижного российского вуза ищет работу в США по специальности “инженер-судостроитель”... Готов доучиваться, переучиваться, сдавать дополнительные экзамены, начинать работу техником или механиком»; «Ищу работу в США в любом городе. Образование экономическое (получено в США), юридическое (в РФ). Английский свободный, уверенный пользователь ПК». Статья с набором подобных примеров, замечу, имеет в заголовке слова с большим обобщающим смыслом: «Поколение на выезд» 1 .

Обратимся в этой связи к данным социологических опросов, которые коллегамисоциологами оцениваются и комментируются с очевидной тревогой относительно будущего страны и ее молодого поколения.

Общероссийское исследование Института социологии РАН и Фонда Ф. Эберта (март - апрель 2012 г.) показало, что ощущение личностной связи с Россией у ее граждан, более всего новых поколений, постепенно утрачивается. И это объясняется атомизацией общества, нарастанием в нем отчужденности людей, все меньшим соответствием его тем идеалам справедливости, которые характерны для русской культуры и являются общими для всех слоев населения. Начинает превалировать формальная связь со страной проживания, человек воспринимает себя не более чем просто гражданином определенного государства. При отсутствии альтернативных разрушению солидарных целей и ценностей отстраненность россиян от своей Родины может со временем только усилиться (Горшков, 2012).

В свою очередь, исследование «Историческое сознание студенческой молодежи в современной России» 2011 г. в Аипецке и Ростове-на-Аону, с одной стороны, подтверждает сохранение у молодых россиян идентификационных ориентиров на патриотизм, но с другой - демонстрирует размывание границ самой идентификации. Большинство опрошенных гордятся тем, что живут в России (68\%), считают себя гражданами (75\%), патриотами страны (73\%), однако на вопрос «Кто я такой?» $64 \%$ выбрали ответ «гражданин России», а 40\% - «просто сказал бы “человек”». При этом в общероссийском контексте авторы исследования прямо соотносят подобный выбор с растущей долей респондентов, допускающих возможность своей эмиграции: в начале 2000-х гг. лишь за какие-то два года она увеличилась на $10 \%$ (Мерзлякова, Аинченко, Овчинникова, 2014: 93).

Среди факторов нередко называют трудовую незанятость молодежи. И может показаться, что повод к тому есть: весной 2015 г., к примеру, в возрастной группе до 25 лет каждый десятый житель числился безработным, но заметим - доля неработающих без видимых причин в их числе составляла половину (исключая учащихся и беря во внимание только трудоспособных) (Тихонова, 2015: 21), а такой расклад дает совсем иную картину. Здесь речь идет больше о тех, кто принципиально не хочет работать, их есть кому кормить и им безразличны нужды Родины - для них она сама по себе, а они - сами по себе. И это объективное отражение царящей в обществе нравственной анархии, рефлексия на двойную мораль. Неслучайно все труднее различать те государственные интересы, на которые, собственно, и должна нацеливать своих воспитанников отечественная образовательная система.

Культ прагматизма, личной выгоды, пренебрежение общественными интересами - естественный продукт мировоззренческой (идеологической) ущербности, 
нравственной слабости, ограниченности жизненных ориентиров нынешних школьников и студентов. Насколько актуальна для воспитывающей среды вуза эта тема, свидетельствуют материалы всероссийских исследований Института социологии PAH (октябрь 2014 г. и март 2015 г.). Весьма значительная часть россиян серьезно опасается нравственной деградации нации: 50\% заявили о сильной тревоге и даже страхе, $38 \%$ - о некотором беспокойстве. Аишь $12 \%$ опрошенных не испытывают по этому поводу беспокойства (Петухов, 2015: 29).

На практике корреляцию общественных интересов, патриотизма и нравственных качеств сменяющих друг друга поколений лучше видят непосредственно педагоги из глубинки, в первую очередь сельской. Оказавшаяся в роли добровольного подвижника доктор педагогических наук Валентина Безрукова рассказала в «Аитературной газете» о своей работе в поселковой школе Ульяновской области, где ей пришлось в конце концов согласиться с жестоким для себя и коллег выводом: в государстве с двойной моралью говорить о нравственном воспитании бессмысленно, оно всегда будет сизифовым трудом. Как воспитывать патриотизм вне нравственности, оторвавшись от нее? Причем требуя патриотизма преимущественно от низов и не пытаясь искать проявления действительной любви к Родине, нравственных подвигов на многоярусной административной вертикали. Нельзя забывать, что патриотизм это не только чье-то геройство, но прежде всего повседневное дело. Полезное для тех, кого любишь, кого бережешь, за кого болеешь. Перебежчиков и предателей много, однако и верных Отечеству еще немало. И нужно выстраивать, призывает педагог, свое народное воспитание как противодействие злу².

\section{АИЦЕЯ АОАГИЙ САЕА}

Сократ за несколько столетий до новой әры отмечал: «Воспитание - дело трудное, и улучшение его условий - одна из священных обязанностей каждого человека, ибо нет ничего более важного, как образование самого себя и своих близких» (Мудрость тысячелетий ..., 2002: 81). Аругой философ, но уже более близкого нам XIX в. Р. Эмерсон, столь же глобально подходя к институту воспитания и его общественной роли, подчеркивал: «Истинный показатель цивилизации - не уровень богатства и образования, не величина городов, не обилие урожая, а облик человека, воспитыљаемого страной» (Афоризмы ..., 1985: 73; курсив наш. - Б. У.).

Руководящее участие государства в заданном общественными интересами создании образовательно-воспитывающей среды, может быть, неожиданно для многих обнаруживается в концепции построения Царскосельского лицея пушкинской поры (1811-1817) - учебного заведения университетского типа, имевшего целью «образование юношества, особенно предназначенного к важным частям службы государства» (Равкин, 1993: 28).

В исследованиях, посвященных лицейским годам жизни А. С. Пушкина, наглядно демонстрируется влияние среды на мировоззрение и характер воспитанников причем среда присутствует в самом широком формате, начиная от товарищеской (на уровне общения лицеистов) до контактов с императорским двором, событий внутри страны.

За всеми деталями воспитывающей лицейской среды 3. И. Равкин видит определенные зависимые связи и закономерности. Учебная среда и принципы воспитания не вправе предполагать возможность морального унижения воспитанников. В понятие нравственных наук, как их квалифицировали в лицее, входят те познания, кото- 
рые относятся к положению человека в обществе, его восприятию духовных ценностей и морали, прав и обязанностей гражданина, способности защищать семью и общество. Воспитание предполагает индивидуальный подход, а следовательно, и неизменной будет проблема выбора наставников, обладающих не только знаниями, но и талантом психолога, методиста. Учебный процесс предполагает непрерывное единство обучения и нравственного воспитания. Отсюда естественное стремление к формированию в стенах учебного заведения мировоззренческих и духовных ориентиров (там же: 60).

Эти выводы вполне можно обобщить как модельную основу для современной образовательной практики.

Причем для параллелей с нынешним днем, на мой взгляд, крайне важно, что лицей пушкинской поры имел в виду в первую очередь гражданское воспитание, ориентировал на патриотизм, формирование психологии государственника, защитника Отечества. И надо заметить, этому курсу следовали, как правило, и другие учебные заведения XIX в. в России.

Показательно, к примеру, насколько склонны были демонстрировать свою «государственность» в Московском университете (Вострышев, 1999: 113-117), где студенты имели особый мундир и шпагу, а за их образом жизни наблюдали (очень строго) специальные люди - инспектор и субинспекторы, по-современному - воспитатели. Существовала, по сути, своя корпоративная система, претендовавшая на ответственность за соблюдение студенческой кастой норм нравственности, учебного порядка, гражданской сознательности. Студента не мог арестовать ни квартальный, ни оберполицмейстер города, поскольку презумпцию невиновности заранее подразумевали добровольно взятые на себя университетом высокие моральные обязательства.

\section{ОБЩИЕ ВЕКТОРЫ И АИЧНАЯ ПААНКА ВЫСОТЫ}

Не будем лукавить: учат всегда с иелью. Какова и у кого эта цель сегодня? Если бы у нас был внятный ответ на этот вопрос, то было бы, полагаю, гораздо легче определить и задачи образования, и потребности (направления) воспитания будущих специалистов в семье, школе и вузе.

В Федеральном законе «Об образовании в Российской Федерации» прямо записано, что «образование - единый целенаправленный процесс воспитания и обучения, являющийся общественно значимым благом и осуществляемый в интересах человека, семьи, общества и государства, а также совокупность приобретаемых знаний, умений, навыков, ценностных установок, опыта деятельности и компетенции определенных объема и сложности в целях интеллектуального, духовно-нравственного, творческого, физического и (или) профессионального развития человека, удовлетворения его образовательных потребностей и интересов» ${ }^{3}$. Вкладывали ли разработчики закона особо значимый смысл в постановку слова «воспитания» впереди слова «обучения», но в дальнейшем тексте их расшифровка, на мой взгляд, не оставляет сомнений по поводу приоритетности одного из них в едином по назначению процессе: «воспитание - деятельность, направленная на развитие личности, создание условий для самоопределения и социализации обучающегося на основе социокультурных, духовно-нравственных ценностей и принятых в обществе правил и норм поведения в интересах человека, семьи, общества и государства ${ }^{4}$, в то время как «обучение - целенаправленный процесс организации деятельности обучающихся по овладению знаниями, умениями, навыками и компетенцией, приобретению 
опыта деятельности, развитию способностей, приобретению опыта применения знаний в повседневной жизни и формированию у обучающихся мотивации получения образования в течение всей жизни» ${ }^{5}$.

Закон дает понять главное: воспитание не просто солидарный с обучением процесс, ему предназначено выполнять важнейшую целевую установку: готовить будущего специалиста к деятельности в интересах своей страны (а как иначе воспринимать «интересы человека, семьи, общества и государства» или задачу социализации в ходе воспитания?).

Такой подход диктует выбрать в качестве основных направлений воспитания в школах и вузах (а по сути, и базовой идеологии) формирование у воспитанников трех обязательных качеств:

- гражданственности (подразумевая в первую очередь осознанное подчинение установленным обществом и государством нормам и правилам жизнедеятельности, правам и обязанностям гражданина, но на том социализационном уровне, который предполагает готовность функционировать в общественных интересах);

- nатриотизма (чувства любви к Родине, своему народу, готовности защищать их интересы в самых разных сферах и ситуациях, в том числе и с оружием в руках);

- нравственности с приоритетом не абстрактных ценностей, а личной ответственности, личного примера, мотивами профессионального долга, высокого социального смысла (включая невозможность продать свои знания, труд за рубеж в разрез с интересами обучившей тебя Родины).

По моим наблюдениям, именно вокруг схожей тематики концентрируется внимание исследователей. Например, опрос первокурсников Красноярского государственного медицинского университета (ноябрь 2014 г.) подтвердил понимание большинством из них значимости развития гражданских качеств - лишь $14 \%$ из них не считают обязательным формировать гражданско-патриотические ценности. Причем подчеркну такую существенную деталь: наиболее важным фактором гражданско-патриотического воспитания выступают для студентов вуза примеры патриотизма и ярко выраженная гражданская позиция со стороны как раз университетских сотрудников, преподавателей, известных врачей (Гаврилюк, Зотин, Константинова, 2015: 36).

Разумеется, кроме влияния вузовской среды эти направления воспитания должны быть близки и родительской семье студента, поскольку она тоже обозначена в законе участником и носителем общих образовательных и воспитательных целей. Но сравнительный социологический анализ (2006 и 2011 гг.), проведенный в Ростове-на-Аону и Ростовской области, показал, что установки, транслируемые семьей, могут противоречить задачам социализации, гражданского воспитания студентов, да и сам вуз порой усиливает возникающие противоречия, пытаясь ориентироваться одновременно и на интересы семьи, и на потребности работодателей, и на приоритеты, декларируемые государством. В результате исследователи вынуждены констатировать: действия семьи и высшей школы скорее сейчас разновекторны, чем находятся в одной плоскости (Филоненко, Мепин, 2013: 77).

По-моему, концентрация на предлагаемых трех обязательных качествах, которые призван формировать вуз как воспитывающий субъект государственной системы подготовки преданных своей стране кадров, сможет нивелировать разновекторность целевого и ценностного ориентира для семьи, школы, вуза, общества и государства. 
Более того, подобный вариант приблизит к тому пониманию педагогики, которое демонстрировал А. С. Макаренко, когда предлагал отказаться от ее трактовки как «детской» и делать «педагогикой общества» (куда естественным образом врастала бы и разновозрастная, пожизненная социализация) (Макаренко, 1986: 164). К тому же станет меньше поводов к бесконечным и ни к чему не обязывающим дискуссиям в педагогических изданиях. Представляется, например, спорным называть критерием при оценке обучающей способности школы условия, когда детям интересно учиться и они могут самостоятельно прогнозировать результаты своей деятельности, и уповать при этом на «межпредметный подход с практико-ориентированным характером» (Филонов, 2014: 24-30).

Конечно, мало выделить три главенствующих качества, внимание к которым определяет цели воспитания в учебном заведении. Надо еще и обозначить показатели, могущие лаконично, оперативно фиксировать статистически сопоставимые данные Аля оценки воспитанности студента.

Строя сходную по своей направленности структуру компонентов воспитания в вузе, А. В. Беляев (у него в качестве третьего компонента фигурирует национальная и социальная идентичность) предлагает набор оценочных показателей, в числе которых репутация вуза, конкурентоспособность выпускников на рынке труда, сплоченность коллектива академической группы, уровень общей культуры студентов и т. д. (Беляев, 2014: 56-62). Специально называю некоторые «показатели», чтобы стало ясно, сколько потребуется времени, сил и штатных единиц, чтобы наладить элементарный учет и анализ возникающего информационного массива.

Исследуя проблемы воспитательной работы в вузе, В. В. Байлук разработал модель качеств личности студента. Исходя из этой модели, ученый вводит четыре уровня его воспитанности: нулевой, низкий, средний, высокий. Нулевой уровень воспитанности он связывает с отсутствием у студента определенного качества (например, с несформированностью чувства ответственности). Низкий уровень характеризуется проявлением того или иного качества от случая к случаю (лишь иногда проявляет добросовестность в учебном труде). Средний уровень связан больше с проявлением того или иного качества, чем с непроявлением (например, студент в целом может быть добросовестным, но периодически проявлять и недобросовестность). Высокий уровень характеризуется полнотой проявления всех качеств личности. По мнению В. В. Байлука, знание студентом уровня своей воспитанности является основой для построения индивидуального проекта самовоспитания (Байлук, 2007: 486-487).

Мною предлагаются следующие показатели действенности воспитательного процесса в вузе.

1. Наличие (проявления) гражданственности (гражданских качеств) студента определяют:

а) оценки в зачетной книжке студента по общественным наукам (прежде всего правовым, историческим, экологическим и т. п.);

б) мера участия в гражданских акциях, проводимых вузом;

в) соблюдение студентом паспортного, визового и туристического режимов, достойное выполнение представительских функций за рубежом и на международных форумах (по зарубежным студенческим программам обмена);

2. Наличие (проявления) патриотизма фиксируется:

а) фактами защиты интересов Родины в неординарных ситуациях; 
б) фактами участия в безвозмездных акциях, деятельности студенческих трудовых отрядов, донорстве, благотворительности, волонтерстве;

в) выполнением тех или иных форм воинской повинности;

г) готовностью по окончании вуза работать в стране.

3. Наличие (пролвления) нравственности оценивается:

a) официальной статистикой нарушений студентом дисциплины, норм права, правил общежития;

б) содержанием текстов характеристик от лица руководителей вуза, общественных организаций;

в) отсутствием в среде жизнедеятельности конфликтов, судебных дел, общественных порицаний в студенческой группе.

На основе таких данных ежегодно до окончания учебы в вузе может определяться мера воспитанности студента по привычной для педагогов пятибалльной шкале. Что касается возможности проследить эффективность воспитательных воздействий вуза на выпускника в период его трудовой карьеры (в том числе по критерию «бросил Родину»), то выборочно, силами социологов, это делать удастся, хотя тотальное отслеживание вряд ли возможно.

\section{ЗАКАЮЧЕНИЕ}

Объединяя изложенное с нашими ранее высказанными суждениями (Усманов, 2015: 87-96), можно сделать следующий вывод: главный критерий, а с ним и признак воспитанности выпускника высшей школы - способность понимать и воспроизводить социальные образцы во имя достижения целей общественного развития, единства дичных и общественных интересов, демонстрировать приверженность гражданственности, патриотизму, нравственным нормам и ценностям своего народа, законам страны.

И надо, наконец, признать как неоспоримую аксиому: образованность не может не предполагать воспитанности.

\section{ПРИМЕЧАНИЯ}

${ }^{1}$ Бараникас И. (2017) Поколение на выезд: молодые россияне ищут возможность свалить на Запад// Московский комсомолец. 30 января. С. 3.

2 Безрукова В. (2015) Поколение селфи: Нравственное воспитание как сфера услуг // Аитературная газета. 17-23 декабря. С. 24.

3 Федеральный закон от 29.12.2012 № 273-Ф3 (ред. от 06.02.2020) «Об образовании в Российской Федерации» [Электронный ресурс] // КонсультантПлюс. URL: http://www.consultant.ru/ document/cons_doc_LAW_140174/b819c620a8c698de35861ad4c9d9696ee0c3ee7a/ (дата обращения: 12.01.2020). Курсивом выделено нами. - Б. У.

${ }^{4}$ Там же.

5 Там же.

\section{СПИСОК АИТЕРАТУРЫ}

Афоризмы: По иностранным источникам (1985) / сост. П. П. Петров, Я. В. Берлин. 3-е изд. перераб. и доп. М. : Прогресс. 496 с.

Байлук, В. В. (2007) Человекознание : в 5 кн. Екатеринбург : Изд-во Уральского гос. пед. ун-та. Кн. 5. Принципы и методы воспитания и самовоспитания студентов. 492 с.

Беляев, А. В. (2014) Воспитание студентов в вузе // Педагогика. № 5. С. 54-62.

Великие мыслители - молодым специалистам: ориентиры для профессионала (2015) / сост. Б. Ф. Усманов. Казань : Изд-во Маковского. 100 с. 
Вострышев, М. И. (1999) Московские обыватели. М. : Молодая гвардия. 249 с.

Гаврилюк, О. А., Зотин, А. Г., Константинова, Е. С. (2015) Особенности гражданско-патриотического воспитания студентов университета в современных условиях // 3нание. Понимание. Умение. № 2. С. 33-39.

Горшков, М. К. (2012) «Русская мечта»: опыт социологического измерения // Социологические исследования. № 12. С. 3-11.

Макаренко, А. С. (1986) Педагогические сочинения : в 8 т. М. : Педагогика. Т. 7. 318 с.

Мерзлякова, И. А., Аинченко, А. А., Овчинникова, Э. В. (2014) Об историческом сознании современной студенческой молодежи // Социологические исследования. № 12. С. 89-96.

Мудрость тысячелетий. Энциклопедия (2002) / сост. В. М. Балязин. М. : Олма-пресс. 848 с.

Петухов, В. В. (2015) Российская трансформация и общественная мысль // Социологические исследования. № 12. С. 28-40.

Равкин, 3. И. (1993) Педагогика Царскосельского лицея пушкинской поры (1811-1817 гг.) : историко-педагогический очерк. М. : Изд-во Института теоретической педагогики РАО. 130 с.

Студенту-первокурснику: создай себя сам! Великие мысли великих мыслителей (2016) : сб. афоризмов / сост. Б. Ф. Усманов. М. : РУАН. 55 с.

Тихонова, Н. Е. (2015) Явные и неявные последствия экономических кризисов для россиян // Социологические исследования. №12. С. 16-27.

Филоненко, В. И., Аепин, А. П. (2013) Семья как основной агент базовой социализации студентов вузов // Социологические исследования. № 6. С. 71-77.

Филонов, Г. Н. (2014) Критерии оценки эффективности воспитательного процесса // Педагогика. № 4. С. 24-30.

Усманов, Б. Ф. (2015) Аксиомы воспитания и социальные контексты воспитывающей среды // Знание. Понимание. Умение. № 2. С. 87-96.

Аата поступления: 20.01.2020 2.

\section{UNIVERSITY ENVIRONMENT AND THE DEGREE OF STUDENTS' MANNERLINESS \\ B. F. USMANOV \\ MOSCOW UNIVERSITY FOR THE HUMANITIES}

The paper presents its author's opinion on what system of values and views is necessary for Russian educational institutions, to which the Federal Law "On Education in the Russian Federation" as of 01 September 2013 gave back the function of upbringing. The author reflects whether today's Russian education system has a dominant idea, and how we can measure students' mannerliness. Whereby the essential question remains: who (or what) are we teaching and educating for?

In the author's opinion, the main criterion, as well as the degree of a graduate's mannerliness, is the ability to understand and reproduce social patterns to achieve the aims of social development, the unity of personal and social interests, and also to demonstrate the commitment to citizenship, patriotism, moral norms and values of their people, and the country's laws.

Keywords: university environment; educational environment; issues of upbringing; degree of mannerliness; higher education; traditions of education; Russian education

\section{REFERENCES}

Aforizmy: Po inostrannym istochnikam (1985)/ comp. by P. P. Petrov and Ya. V. Berlin. 3nd ed. Moscow, Progress. 496 p. (In Russ.).

Bailuk, V. V. (2007) Chelovekoznanie : in 5 book. Ekaterinburg, Izd-vo Ural'skogo gos. ped. un-ta. Book 5. Printsipy i metody vospitaniia i samovospitaniia studentov. 492 p. (In Russ.).

Beliaev, A. V. (2014) Vospitanie studentov v vuze. Pedagogika, no. 5, pp. 54-62. (In Russ.).

Velikie mysliteli - molodym spetsialistam: orientiry dlia professionala (2015) / comp. by B. F. Usmanov. Kazan', Izd-vo Makovskogo. 100 p. (In Russ.).

Vostryshev, M. I. (1999) Moskovskie obyvateli. Moscow, Molodaia gvardiia. 249 p. (In Russ.). 
Gavriliuk, O. A., Zotin, A. G. and Konstantinova, E. S. (2015) Osobennosti grazhdansko-patrioticheskogo vospitaniia studentov universiteta v sovremennykh usloviiakh. Znanie. Ponimanie. Umenie, no. 2, pp. 33-39. (In Russ.).

Gorshkov, M. K. (2012) «Russkaia mechta»: opyt sotsiologicheskogo izmereniia. Sotsiologicheskie issledovaniia, no. 12, pp. 3-11.

Makarenko, A. S. (1986) Pedagogicheskie sochineniia : in 8 vol. Moscow, Pedagogika. Vol. 7. 318 p. (In Russ.).

Merzliakova, I. L., Linchenko, A. A. and Ovchinnikova, E. V. (2014) Ob istoricheskom soznanii sovremennoi studencheskoi molodezhi. Sotsiologicheskie issledovaniia, no. 12, pp. 89-96. (In Russ.).

Mudrost' tysiacbeletii. Entsiklopediia (2002) / comp. by V. M. Baliazin. Moscow, Olma-press. 848 p. (In Russ.).

Petukhov, V. V. (2015) Rossiiskaia transformatsiia i obshchestvennaia mysl'. Sotsiologicheskie issledovaniia, no. 12, pp. 28-40. (In Russ.).

Ravkin, Z. I. (1993) Pedagogika Tsarskosel'skogo litseia pushkinskoi pory (1811-1817 gg.) : istoriko-pedagogicheskii ocherk. Moscow, Izd-vo Instituta teoreticheskoi pedagogiki RAO. 130 p. (In Russ.).

Studentu-pervokursniku: sozdai sebia sam! Velikie mysli velikikb myslitelei (2016) : sb. aforizmov / comp. by B. F. Usmanov. Moscow, RUDN. 55 p. (In Russ.).

Tikhonova, N. E. (2015) Iavnye i neiavnye posledstviia ekonomicheskikh krizisov dlia rossiian. Sotsiologicheskie issledovaniia, no. 12, pp. 16-27. (In Russ.).

Filonenko, V. I. and Lepin, A. P. (2013) Sem'ia kak osnovnoi agent bazovoi sotsializatsii studentov vuzov. Sotsiologicheskie issledovaniia, no. 6, pp. 71-77. (In Russ.).

Filonov, G. N. (2014) Kriterii otsenki effektivnosti vospitatel'nogo protsessa. Pedagogika, no. 4, pp. 24-30.

Usmanov, B. F. (2015) Aksiomy vospitaniia i sotsial'nye konteksty vospityvaiushchei sredy. Znanie. Ponimanie. Umenie, no. 2, pp. 87-96.

Submission date: 20.01.2020.

Усманов Борис Фатыхович - доктор социологических наук, профессор, профессор кафедры социологии Московского гуманитарного университета. ААрес: 111395, Россия, г. Москва, ул. Юности, д. 5, корп. 3. Тел.: +7 (499) 374-50-61. Эл. адрес: usmanov1939@mail.ru

Usmanov Boris Fatykhovich, Doctor of Sociology, Professor, Professor, Department of Sociology, Moscow University for the Humanities. Postal address: 5, Yunosti St., Moscow, Russian Federation, 111395. Tel.: +7 (499) 374-50-61. E-mail: usmanov1939@mail.ru 